\title{
Default Risk and Equity Returns: A \\ Comparison of the Bank-Based German and \\ the U.S. Financial System
}

Christoph Breig and Ralf Elsas

Discussion paper 2009 - 12

August 2009

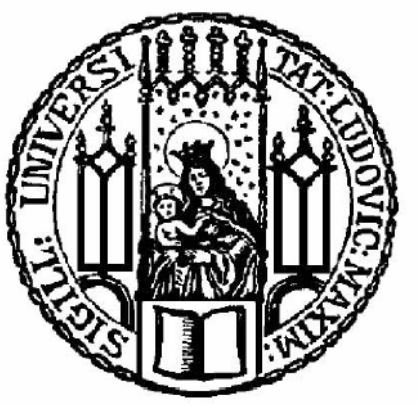

Munich School of Management

University of Munich

Fakultät für Betriebswirtschaft

Ludwig-Maximilians-Universität München

Online at http://epub.ub.uni-muenchen.de/ 


\title{
Default Risk and Equity Returns: A Comparison of the Bank-Based German and the U.S. Financial System
}

\begin{abstract}
We address the question whether the impact of default risk on equity returns depends on the financial system firms operate in. We compare results from asset pricing tests for the German and the U.S. stock markets, where Germany is the prime-example for a bank-based financial system. We find that a higher firm default risk systematically leads to lower returns in both capital markets. This contradicts results for the U.S. by Vassalou/Xing (2004), but we show that their default risk factor looses its explanatory power if one includes a default risk factor measured as a factor mimicking portfolio, as we do.
\end{abstract}

\section{Introduction}

Over the past decades, most empirical asset pricing literature has had only limited success to find systematic factors explaining stock returns. Empirical factors vary across countries and time-periods and often lack a theoretical justification. Only recently, attention has been paid on the question whether default risk affects equity returns. In this paper, we contribute to this literature by addressing the question whether the impact of default risk on equity returns depends on the financial system firms operate in.

Although default risk primarily is a firm-specific risk factor and thus diversifiable, recent evidence suggests that it also entails a systematic component. There are at least four arguments why default risk could affect equity returns. First, the arbitrage pricing theory, APT, (Ross (1976)) shows that multiple factors may determine expected returns on equity in equilibrium. Since APT does not imply what these factors are, conclusions could be based on the evidence (empirical stylized facts). Denis and Denis (1995) find evidence that default risk is related to macroeconomic factors, other studies indicate a direct effect of default risk on equity returns in the U.S. ${ }^{1}$

Second, more technically, if a firm is leveraged, equity risk (systematic risk and volatility) and therefore expected returns depend on firms' indebtedness, with a non-stationary relationship between equity volatility and the volatility of firm assets (see Galai and Masulis (1976)). Since default risk is ceteris paribus increasing in leverage, equity returns should be related to default risk. Ferguson and Shockley (2003) show that conducting asset pricing tests on equity returns therefore leads to biased estimates of factor sensitivities, with the bias increasing in a firm's relative leverage and distress risk. Moreover,

$\overline{1}$ See for example Dichev (1998), Griffin and Lemmon (2002), Vassalou and Xing (2004), Campello and Chen (2005) or Zhang (2007). 
firm-specific variables that correlate with leverage or default risk will serve as respective instruments, potentially explaining the statistical significance of the size and the book-to-market factor.

Third, changes in the economic environment can lead to cross-sectionally correlated firm and investor behavior, giving rise to non-diversifiable equity return patterns. For example, Fama and French (1996) argue that their SMB and HML factors proxy for financial distress, because if distress risk is crosssectionally correlated, workers with specialized human capital in distressed firms will avoid to invest in other stocks subject to default risk, thus requiring a risk premium. Also, if firms' capital structure decisions are driven by some joint factors, changes in firm leverage will be correlated in the cross-section, thereby leading to non-diversifiable stock return patterns related to leverage. There is a lot of corresponding evidence showing that firms are more likely to issue equity in specific market stages, also discussed as the so-called "hot issue markets" and the "market-timing" explanation for capital structure decisions (see e.g. Loughran and Ritter (1995))

Finally, the modern theory of financial intermediation suggests that in imperfect capital markets with information asymmetries between firm owners, managers, and outside investors, debt can be an efficient way of solving conflicts of interest between these parties (see e.g. Shleifer and Vishny (1997)). Hence, characteristics of debt can directly affect firm performance, and therefore expected equity returns, and this effect may be influenced by the financial system the firms operate in.

In this paper, we compare the impact of default risk on equity returns for the U.S. and the German stock market. The comparison between the U.S. and Germany is interesting in the context of default risk, since the German financial system is the prime example of a bank-based financial system, where the role of banks as an active mechanism of corporate governance (in particular through debt financing, equity holdings, and representation in the supervisory board) is significant even for large, exchange listed firms (Gorton and Schmid (2000)). Hence, if the sensitivity of equity returns against a systematic default factor were driven by the relevance and composition of corporate debt, then one should expect that this effect is even more (price) relevant in a bank-based financial system than in the U.S. ${ }^{2}$

Similar to the seminal study by Vassalou and Xing (2004), we measure default risk by an implementation of Merton's option-pricing model for the value of equity to avoid using default risk measures based on accounting information, which give rise to problems due to the inherently backward-looking orientation of annual reports, accounting discretion, and the lack of timeliness of infor-

\footnotetext{
${ }^{2}$ In addition, the German capital market has been barely studied empirically, providing for a possibility to validate other empirical results on the impact of default risk on equity returns.
} 
mation. ${ }^{3}$ The Merton (1974) model uses the market value of equity and an estimate of the market value of debt to calculate default risk, thus relying on the most frequently available and forward looking information to assess the likelihood that a firm defaults in the future. Furthermore, the Merton (1974) model takes into account the volatility of a firm's assets. Firms with similar leverage can have very different default probabilities due to asset volatility, which is typically not considered by accounting models. Since asset volatility is a key input to the option pricing formula, this constitutes another advantage of our methodology.

We find evidence consistent with default risk being a systematic factor similarly priced in both capital markets. Our estimates suggest that a higher firm default risk leads to lower returns, which contradicts some previous results for the U.S. by Vassalou/Xing (2004). However, their default risk factor looses its explanatory power when tested against the excess return measure suggested in this paper, and this factor systematically helps pricing stocks in the U.S. and Germany.

Still, we do find evidence for an impact of financial system characteristics on the impact of default risk on equity returns. We find evidence that the composition of corporate debt affects equity returns in Germany since firms' default risk sensitivities are attenuated the more a firm depends on bank debt financing.

The paper is organized as follows. In the next section, we present the methodology used to estimate default risk of firms and to construct the default risk factor used in the subsequent asset pricing tests. Section 3 presents the data and descriptive statistics on the factors used to explain equity returns, with an emphasis on the distress factor. Section 4 provides results of the asset pricing tests on the German capital market. In Section 5, we present the test of our default risk factor for the U.S. market and examine determinants of firms' default factor sensitivities. Section 6 concludes.

\section{Methodology}

\subsection{Estimating Firms' Probabilities of Default}

Economically, default occurs if the value of a firm's assets hits a default barrier, which is often assumed being equal to the nominal value of debt due at some point in time. The probability of default thus depends on unobservable firm characteristics: (market-value based) leverage, asset value and asset

$\overline{3}$ These problems might also explain the contradictory findings in previous studies based on Altman's Z-Score (Altman (1968)), Ohlson's O-Score model (Ohlson (1980)), or bond spreads. 
volatility. To use timely and forward-looking information, these characteristics are inferred from daily equity market values, using the relationship postulated by Merton (1974). A firm's equity at time $t$ is viewed as a call option on the firm's assets, where the book value of debt due at time $t+T$ ( $T$ is equal to the time to expiration of the option) is the strike price, $D$. Consequently, if the value of assets is equal to or less than $D$ at maturity, the value of equity is zero. Merton assumes that the market value of a firm's assets follows a Geometric Brownian Motion and satisfies the stochastic differential equation: ${ }^{4}$

$$
d A_{t}=\mu_{A} A_{t} d t+\sigma_{A} A_{t} d W_{t}
$$

where $A_{t}$ denotes the firm's asset value at time $t$ with an instantaneous drift $\mu_{A}$, and an instantaneous volatility $\sigma_{A}$. $W_{t}$ is a standard Wiener process. The equity value $E_{t}$ then follows from the Black and Scholes (1973) formula:

$$
E_{t}=A_{t} \Phi\left(d_{1, t}\right)-D e^{-r_{f} T} \Phi\left(d_{2, t}\right)
$$

$D$ describes the strike price of the call, $\Phi(s)$ denotes the value of the standard normal distribution at $s$ and $r_{f}$ is the risk-free rate. $d_{1, t}$ and $d_{2, t}$ are given by:

$$
\begin{gathered}
d_{1, t}=\frac{\ln \left(\frac{A_{t}}{D}\right)+\left[r_{f}+\frac{1}{2} \sigma_{A}^{2}\right] T}{\sigma_{A} \sqrt{T}} \\
d_{2, t}=d_{1, t}-\sigma_{A} \sqrt{T}
\end{gathered}
$$

In the empirical implementation, the unobservable variables $\sigma_{A}$ and $A_{t}$ can be iteratively estimated for each day in the observation period of our stocks. ${ }^{5}$ For each point in time $t$, the preceding 250 trading days are used to estimate $\sigma_{E}$ as an initial guess for the asset volatility, $\sigma_{A}$. Applying the Black/Scholes formula, we get a series of asset values, $A_{t}$. These are in turn used to get an updated estimate of $\sigma_{A}$. This estimate is used for the next iteration, and the procedure is continued until the $\sigma_{A}$ estimate converges with a tolerance level of $10 e-6$. The final volatility estimate is then used to calculate the asset value estimate, using again equation (2).

The firm's probability of default at day $t, P D_{t}$, follows from the probability that the asset price $A_{t+T}$ is equal to or less than the strike price (default barrier) $D$ given asset price $A_{t}$ :

$$
P D_{t}=\operatorname{Prob}\left(A_{t+T} \leq D \mid A_{t}\right)=\operatorname{Prob}\left(\ln \left(A_{t+T}\right) \leq \ln (D) \mid A_{t}\right)
$$

\footnotetext{
$\overline{4}$ See Vassalou and Xing (2004).

5 This approach is similar to the one used by Vassalou and Xing (2004) and KMV (see Crosbie and Bohn (2003)).
} 
Using the Geometric Brownian Motion assumption for the asset value process, the probability of default is equal to

$$
P D_{t}=\Phi\left(-\frac{\ln \left(\frac{A_{t}}{D}\right)+\left(\mu_{A}-\frac{1}{2} \sigma_{A}^{2}\right) T}{\sigma_{A} \sqrt{T}}\right)
$$

Alternatively, one can calculate the so-called distance-to-default (DD) as

$$
D D_{t}=\frac{\ln \left(\frac{A_{t}}{D}\right)+\left(\mu_{A}-\frac{1}{2} \sigma_{A}^{2}\right) T}{\sigma_{A} \sqrt{T}}
$$

Note that $\Phi$ denotes a standard normal distribution but empirical analyses find better results using a Student's t-distribution function. ${ }^{6}$

The PD measures a firms probability of default at $t+T$ under the real measure, that is, we use $\mu_{A}$ rather than the risk free rate as the drift term. ${ }^{7}$ The distance-to-default (DD) measures how many standard deviations the asset value needs to drop to meet the debt value, which triggers default. Hence, a lower DD translates into a higher probability of default, and vice versa. In the following, we use the distance-to-default to sort firms on their default risk. This particularly solves the problem, that very frequently observed high values of DD correspond to very low probability of defaults, which might raise numerical issues in calculations.

\subsection{Factor Construction and Test Assets}

The empirical modeling of our study uses the market model, the Fama/French three factor model, and two alternative specifications that augment the Fama/French factors by one particular variant of a default risk factor.

We construct the default risk factors using two simple approaches. The first approach follows the standard Fama and French (1993) methodology. More precisely, we create a SIZE list sorted on firms market capitalization, a BM list sorted on the book-to-market equity ratio, and a firm list sorted by the distance-to-default (DD) of individual companies. In addition, we divide the three lists into big (B) and small (S) companies $^{8}$, then companies with low (L) and high (H) BM and finally firms with low (l), medium (m) and high (h) distance-to-default. Thus, each firm receives three attributes SIZE/BM/DD. For example, a firm can be small with low BM and low distance-to-default which makes it a member of the company portfolio with the attributes $\mathrm{S} / \mathrm{L} / \mathrm{l}$. The intersections of the three decomposed lists constitute 12 ( $2 \times 2 \times 3)$ possi-

\footnotetext{
6 See Furfine and Rosen (2009).

$7 \mu_{A}$ is estimated from the time series of asset values and meets the condition $\mu_{A}=$ $\max \left[r_{f}, \hat{\mu}_{A}\right]$, to avoid expected returns lower than the risk free rate.

8 Big companies are companies with market values greater than the median over firms at some point in time.
} 
ble portfolios of firms with uniform attributes within each portfolio. Therefore we define:

$$
\begin{aligned}
D E F_{t}= & {\left[R_{S / L / h, t}+\ldots+R_{B / H / h, t}\right] / 4-} \\
& {\left[R_{S / L / l, t}+\ldots+R_{B / H / l, t}\right] / 4 }
\end{aligned}
$$

The second default factor is constructed as proposed by Vassalou and Xing (2004).

$$
\Delta\left(S V_{t}\right)=E_{i}\left[1-P D_{i, t}\right]-E_{i}\left[1-P D_{i, t-1}\right] \quad i=1 \ldots N_{C, t}
$$

where $\Delta\left(S V_{t}\right)$ denotes the change of the aggregate survival rate. $E_{i}($.$) is the$ simple average over all companies, $N_{C, t}$, included at time t.

Note the crucial difference between the two variants of default risk factors: While the DEF factor is a factor-mimicking, self-financing portfolio return analogous to HML and SMB, the variant used by Vassalou and Xing (2004) is no return, but rather a measure of the change in aggregate default risk. Most importantly, $\Delta\left(S V_{t}\right)$ is no market price of risk, which renders the use of the traditional time series based asset pricing test (where excess returns of test assets are regressed on the factors) infeasible, since there is no reason to expect an intercept of zero. Recall that the intercept of such an excess return regression is the measure of systematic returns not explained by the empirical asset pricing model.

The construction of the remaining three factors, the Fama/French factors, namely RMRF (market factor), SMB (small minus big) and HML (high minus low) follows the traditional way. RMRF is expressed by the return of a proxy for the market portfolio that is in Germany the Composite DAX (CDAX) minus the risk free rate, though we cross check all results with a self-constructed value-weighted market factor. The SMB and HML factor are created using the methodology discussed in detail in Fama and French (1993).

Finally, the test assets used in the asset pricing test are constructed similar to the 12 portfolios described earlier. As proposed by Vassalou and Xing (2004), to capture the three effects with assets providing maximum dispersion regarding the factors, we would like to use a $3 \times 3 \times 3$ form of independent sorts. Due to the limited number of firms on the German stock market, we again use a set of test assets resulting from a $2 \times 2 \times 3$ sort. Hence, the SIZE list is divided into two parts, $\operatorname{Small}(\mathrm{S})$ and $\operatorname{Big}(\mathrm{B})$, the BM list is also divided into two parts, $\operatorname{Low}(\mathrm{L})$ and $\operatorname{High}(\mathrm{H})$ and finally the DD list is divided into three parts, low $\mathrm{DD}(\mathrm{l})$, medium $\mathrm{DD}(\mathrm{m})$ and high $\mathrm{DD}(\mathrm{h})$. Corresponding portfolio returns are again computed according to Fama and French (1993). 


\subsection{Econometric Methodology}

One objective of the paper is to test whether default risk is systematically priced in the German and American capital market. We use the Generalized Method of Moments (GMM) methodology by Hansen (1982) and employ the asymptotically optimal weighting matrix throughout. To allow for comparisons of our results with previous studies, we conduct both a simultaneous timeseries and cross-sectional test, and a stochastic-discount-factor test as outlined by Cochrane (2005).

The simultaneous time-series and cross-section test basically estimates portfolio factor sensitivities using time-series regressions and then conducts crosssectional regressions of portfolio returns on (estimated) factor sensitivities to estimate factor risk premia. Doing this simultaneously in the GMM framework allows to correct inference for the error-in-variables bias inherent in the cross-sectional regressions.

The stochastic discount factor framework estimates a linear function of the factors, i.e. the pricing kernel, trying to explain which factors help pricing future cashflows of assets. The pricing kernel is the stochastic discount factor that translates future uncertain cashflows (or returns) into today's observed prices. Average prices should be a linear function of covariances between returns and factors. The GMM estimate therefore corresponds to a linear crosssectional regression of sample average returns on covariances of asset returns with factors across assets. In the appendix, both methods are described in detail.

\section{Data and Summary Statistics}

Our sample of German listed firms consists of 1055 firms over the period July 1990 to June 2006 (1990:7 to 2006:6). Daily price data are from Datastream, whereas data on annual reports are taken from Worldscope. The German Central Bank (Deutsche Bundesbank) provides the daily time series of the risk free rate, the one-month FIBOR/EURIBOR. All returns are adjusted for capital measures and dividends. ${ }^{9}$

We examine only stocks with ordinary common equity and exclude financial firms, similar to Fama and French (1993). ${ }^{10}$ Companies are included into our yearly portfolio constructions if they have a return for June $\tau$, information on

\footnotetext{
9 We have spend considerable effort to cross-check and correct the Datastream data for the typical problems of this database, like mistyped values, repeated values for holidays, entered values for already delisted firms etc. For an overview on typical problems associated with Datastream, see Ince and Porter (2006).

${ }^{10}$ ADRs and REITs are not available on the German stock market for our observation period.
} 
Table 1

Number of Companies per Year

The table reports the number of German companies contained in the sample. A company is only reported if and only if it has at least one non-empty return for June of the correspondent year $\tau$ in Datastream and a book-to-market equity value in December $\tau-1$. The book-to-market equity value in December $\tau-1$ is calculated using the fiscal year end book equity of year $\tau-1$ divided by firm's market value of December $\tau-1$. Book equity is Worldscope's total assets, minus liabilities, plus balance sheet deferred taxes, minus preferred stock (if available).

\begin{tabular}{cccc}
\hline \hline year & \# of companies & year & \# of companies \\
\hline 1990 & 203 & 1998 & 380 \\
1991 & 231 & 1999 & 414 \\
1992 & 226 & 2000 & 531 \\
1993 & 231 & 2001 & 640 \\
1994 & 281 & 2002 & 618 \\
1995 & 279 & 2003 & 529 \\
1996 & 311 & 2004 & 503 \\
1997 & 338 & 2005 & 534 \\
\hline \hline
\end{tabular}

total debt, total common equity, preferred stock and deferred taxes in year $\tau-1$, and market capitalization available in December $\tau-1$. The resulting number of firms over time is reported in Table 1 . Note that the numbers of companies within this table are used to compute the Fama/French factors. However, for the calculation of the default risk factors, the sample reduces to a total of 868 companies as the necessary information to estimate distance-todefaults eliminates more observations.

\subsection{Portfolio Returns and Default Risk Characteristics}

For descriptive purposes, Table 2 summarizes the characteristics of the 12 test portfolios over the period 1990:7 to 2006:6. The table shows for each portfolio averages of monthly total market capitalization in percent, book-tomarket, number of firms, and distance-to-default.

Panel A shows the average number of Firms within the portfolios. There is some tendency for companies with low DD to concentrate within small firms' portfolios. For example, the number of companies of the Small/Low DD group is on average (44.501), ${ }^{11}$ and about 7.5 times larger than the number of companies within the Big/Low DD, which is on average 6.063. An inverse pattern can be found for high DD firms that concentrate within Big portfolios (41.407 vs. 9.032). Panel A also shows the average distance-to-default of the 12 portfolios, where a high DD corresponds to low default risk, and vice versa.

\footnotetext{
${ }^{11}$ The average of the number of companies of the Small/Low DD group is calculated as follows: $(31.688+57.313) / 2=44.501$.
} 
Table 2

Characteristics of 12 Portfolios formed on SIZE, BM and DD

At the end of each June from 1990 to 2005, we form 12 portfolios as the intersections of independent sorts into two SIZE groups, two BM groups and three DD groups $(2 \times 2$ $\mathrm{x} 3$ attribute structure). For each portfolio, the table shows average across the months of 1990:7 to 2006:6 of "Number of firms" and "Average DD" in Panel A, "Percent of Total Market Cap" and "Average BM" in Panel B. The labels of the tables denote the portfolio attributes "SIZE \& BM" on the left and "DD" on the upper side.

Panel A: Average Number of Firms and DD within the 12 Portfolios sorted on SIZE, BM and DD

\begin{tabular}{lccccccc}
\hline \hline & \multicolumn{3}{c}{ Average Number of Firms } & \multicolumn{3}{c}{ Average DD } \\
\hline & LowDD & MedDD & HighDD & Sum & LowDD & MedDD & HighDD \\
\hline Small \& LowBM & 31.688 & 18.688 & 10.000 & 60.375 & 2.559 & 6.154 & 13.725 \\
Small \& HighBM & 57.313 & 25.625 & 8.063 & 91.000 & 2.665 & 6.072 & 12.857 \\
Big \& LowBM & 5.875 & 28.813 & 56.313 & 91.000 & 3.248 & 6.682 & 15.682 \\
Big \& HighBM & 6.250 & 28.563 & 26.500 & 61.313 & 3.341 & 6.589 & 14.061 \\
Sum & 101.125 & 101.688 & 100.875 & 303.688 & & & \\
\hline \hline
\end{tabular}

Panel B: Size and BM within the 12 Portfolios sorted on SIZE, BM and DD

\begin{tabular}{lccccccc}
\hline \hline & \multicolumn{3}{c}{ Percent of Total Market Cap } & \multicolumn{3}{c}{ Average BM } \\
\hline & LowDD & MedDD & HighDD & Sum & LowDD & MedDD & HighDD \\
\hline Small \& LowBM & 0.442 & 0.425 & 0.456 & 1.323 & 0.134 & 0.342 & 0.307 \\
Small \& HighBM & 0.832 & 0.596 & 0.244 & 1.672 & 1.328 & 1.241 & 1.037 \\
Big \& LowBM & 1.699 & 18.461 & 42.488 & 62.648 & 0.233 & 0.332 & 0.302 \\
Big \& HighBM & 1.915 & 14.510 & 17.932 & 34.357 & 1.050 & 0.998 & 0.880 \\
Sum & 4.889 & 33.992 & 61.120 & 100.000 & & & \\
\hline \hline
\end{tabular}

Table 3 shows average returns of two types of test assets. First, to allow comparisons with previous studies ${ }^{12}$, Panel A provides average returns of 16 portfolios sorted on SIZE and BM (using a 4 x 4 sort). As becomes evident, there is no clear pattern related to the size effect in these descriptive statistics as there is only one significant Small-Big difference. In contrast, the differences regarding the book-to-market ratio are more pronounced. There is a tendency of increasing returns from portfolios with low BM to portfolios with high BM as there are two significant return differences High-Low.

Panel B of Table 3 shows the average returns of portfolios sorted on distanceto-default, firm size and book-to-market, where we use a 2 × 2 × 3 sort. The resulting 12 portfolios constitute the test assets for the asset pricing tests in the next section. There is a strong evidence of increasing returns over all default risk-classes from low DD to high DD. The difference t-test indicates this relationship in all cases to be statically significant.

\subsection{Factor Characteristics}

The descriptive statistics in the preceding section provide an indication that a default risk effect might exist on the German stock market. The univariate tests do not clearly suggest a firm size and BM effect. Firms' default risk

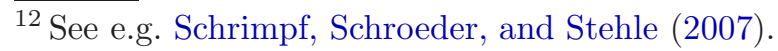


Table 3

Returns of SIZE, BM and DD portfolios

The table shows average returns of different portfolio structures over the period 1990:7 to 2006:6. Panel A shows monthly returns in percent of the 16 value-weighted Fama/French portfolios. Portfolio differences, that is High minus Low and Small minus Big and its tvalues are also displayed; t-values are calculated through a Dummy OLS-Regression with Newey-West standard errors. The dummy is created for two portfolio classes (e.g. big=1 and small $=0$ ). The truncation factor $l$ used within the regression is computed through a rule of thumb $l=\operatorname{ceil}\left(3 / 4 \cdot T^{1 / 3}\right)$. Panel B reports the monthly returns of the $2 \times 2 \mathrm{x}$ 3 test asset system with two SIZE, two BM and three DD classifications. ${ }^{*},{ }^{* *}$ and ${ }^{* * *}$ denotes significance at the 10\%-, 5\%- and 1\%-level, respectively.

Panel A: Returns of the 16 portfolios sorted on SIZE and BM

\begin{tabular}{lcccccc}
\hline \hline & LowBM & 2 & 3 & HighBM & HighBM-LowBM & t-stat \\
\hline Small & 1.594 & 0.096 & 0.596 & 0.637 & -0.957 & $(-1.577)$ \\
2 & 0.085 & -0.127 & 0.045 & 0.443 & 0.358 & $(0.780)$ \\
3 & -0.134 & 0.189 & 0.558 & 0.750 & 0.884 & $\left(1.961^{* *}\right)$ \\
Big & 0.463 & 0.543 & 1.235 & 1.169 & 0.707 & $\left(1.722^{*}\right)$ \\
Small-Big & 1.132 & -0.447 & -0.639 & -0.532 & & \\
t-stat & $\left(1.940^{*}\right)$ & $(-1.036)$ & $(-1.471)$ & $(-1.361)$ & & \\
\hline \hline
\end{tabular}

Panel B: Returns of the 12 portfolios sorted on SIZE, BM and DD

\begin{tabular}{lccccc}
\hline \hline & LowDD & MedDD & HighDD & HighDD-LowDD & t-stat \\
\hline Small \& LowBM & -0.030 & 0.392 & 0.688 & 0.718 & $\left(1.662^{*}\right)$ \\
Small \& HighBM & -0.315 & 0.827 & 0.734 & 1.048 & $\left(1.871^{*}\right)$ \\
Big \& LowBM & 0.432 & -0.662 & 1.374 & 0.942 & $\left(1.856^{*}\right)$ \\
Big \& HighBM & -0.016 & 0.715 & 1.156 & 1.172 & $\left(3.078^{* * *}\right)$ \\
\hline \hline
\end{tabular}

appears only weakly correlated with either BM or SIZE as supported by the correlation coefficients between the factors RMRF, SMB, HML, $\Delta(\mathrm{SV})$, and DEF, reported in Table 4. Here, RMRF denotes the return of the CDAX (the broadest performance index for Germany comprising all firms listed at Frankfurt stock exchange) in excess of the risk-free rate. The other factors are constructed as explained in Section 2.2.

Table 4

Descriptive Statistics of the Factors

The table reports means and standard deviations in percent per month for the period 1990:7 to 2006:6. Included factors are the market factor RMRF, the size factor SMB, the $\mathrm{BM}$ factor, the HML factor, the default factor DEF, and the default factor $\Delta(\mathrm{SV})$. RF denotes the risk free rate. The table also provides correlation coefficients between these factors.

\begin{tabular}{|c|c|c|c|c|c|c|c|c|c|c|}
\hline \multicolumn{5}{|l|}{ Variable } & \multicolumn{6}{|c|}{ Correlations } \\
\hline & mean & std & $\min$ & $\max$ & RMRF & SMB & $\overline{\mathrm{HML}}$ & $\overline{\mathrm{DEF}}$ & $\Delta(\mathrm{SV})$ & $\mathrm{RF}$ \\
\hline RMRF & 0.293 & 5.876 & -24.123 & 19.800 & 1.000 & -0.303 & -0.323 & -0.042 & 0.455 & -0.137 \\
\hline $\mathrm{SMB}$ & -0.478 & 3.635 & -10.612 & 10.925 & & 1.000 & -0.171 & -0.295 & 0.191 & -0.053 \\
\hline HML & 0.335 & 4.152 & -18.459 & 19.777 & & & 1.000 & -0.084 & -0.094 & 0.028 \\
\hline $\mathrm{DEF}$ & 0.754 & 4.092 & -11.546 & 14.591 & & & & 1.000 & -0.197 & 0.043 \\
\hline$\Delta(\mathrm{SV})$ & -0.038 & 0.550 & -2.559 & 1.682 & & & & & 1.000 & -0.066 \\
\hline $\mathrm{RF}$ & 0.379 & 0.199 & 0.168 & 0.823 & & & & & & 1.000 \\
\hline
\end{tabular}

Table 4 shows that the correlation between RMRF, SMB and HML is negative and significant in terms of magnitude. The default-risk factor DEF is almost uncorrelated with the market factor, whereas the $\Delta(\mathrm{SV})$ factor has a 
correlation with the market of about 0.455 . This already points to the fact that these measures are actually quite different. The correlation between the measure of Vassalou and Xing (2004), $\Delta(\mathrm{SV})$, and our excess-return factor DEF is only -0.197 . Recall that $\Delta(\mathrm{SV})$ simply measures the change in aggregate (average) default risk, while DEF constitutes a factor-mimicking portfolio.

Table 4 also provides summary statistics on the factor returns. The average market risk premium over the observation period is only $0.293 \%$ per month. Similar to the results of Schrimpf, Schroeder, and Stehle (2007) for the German capital market, the average premium on the size-factor SMB is negative with $-0.478 \%$ per month. The average premium on the default risk factor DEF is $0.754 \%$ per month. The mean value of Vassalou/Xing's factor $\Delta(\mathrm{SV})$ is close to zero, indicating that the average change in aggregate default risk is fairly small.

Fig. 1. Factor Time-Series

This figure plots the price development of the market factors RMRF, the size factor SMB, the BM factor HML and the default factor DEF. The charts start at time July 1990 at 100. Each time tick represents January of the corresponding year.

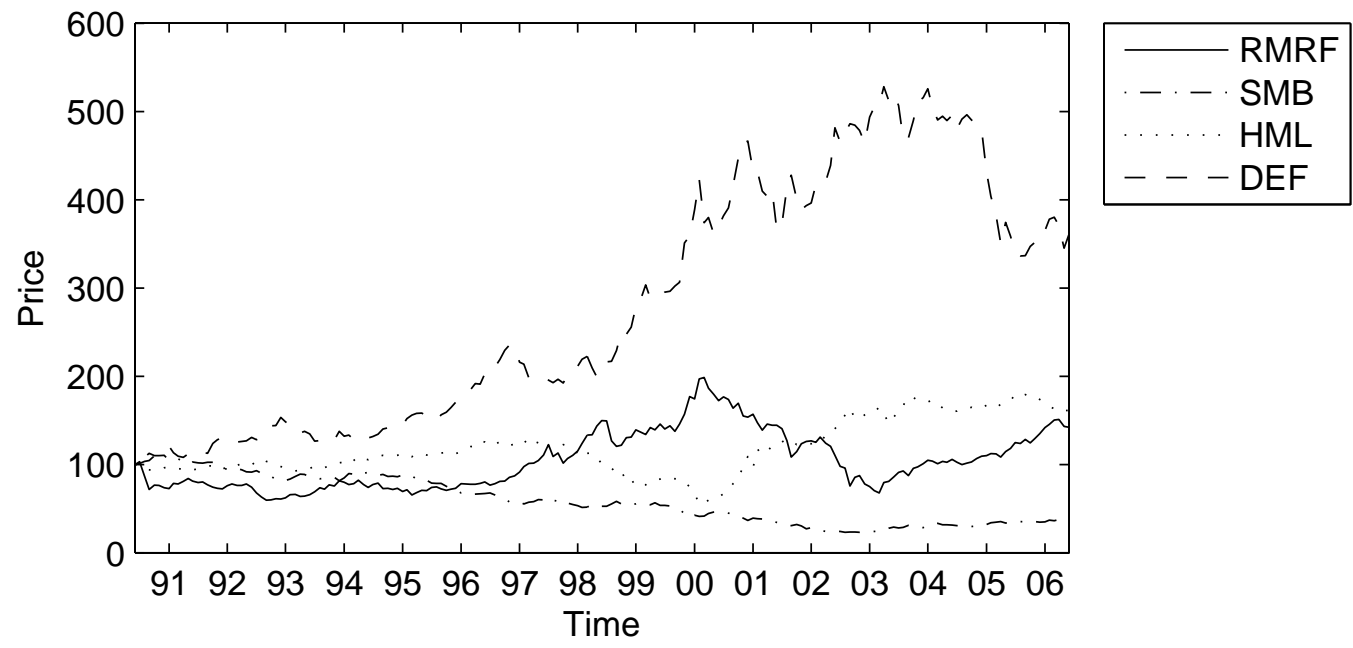

The time-series development of these factors and a first indication of their economic significance can be gained from Figure 1. The figure shows a plot of factor-returns indices (i.e. fictitious "price" series rebased to 100) over our observation period. While the market factor RMRF, HML, and the default risk factor DEF show factor-specific systematic variation and trend behavior, the size factor shows a negative trend and comparatively little variation. 


\section{German Stock Market Results}

\subsection{Time-Series and Cross-Sectional Test}

To test whether default risk is priced in the German capital market, we first consider the simultaneous time-series and cross-sectional GMM model with the moment conditions of equation (10). ${ }^{13}$ Table 5 shows the estimated factor sensitivities for the 12 (2x2x3) test assets sorted on SIZE, BM and DD. The cross-sectional estimates of the risk premia are presented in Table 6.

Table 5 shows coefficient estimates of time-series regressions of test asset (excess) returns on factor returns. Notably, all portfolios with a low distanceto-default (i.e. high default risk) load negatively on the default risk factor DEF, while portfolios containing firms with low default risk load positively. There is no comparable pattern visible for the $\Delta(\mathrm{SV})$ default risk factor proposed by Vassalou and Xing (2004). This demonstrates again that the two factors are very different measures, although they are intended to proxy for the same economic effect.

Panel $\mathrm{C}$ of Table 5 reports the results from a Wald test for the joint significance of the intercept terms of the two regression systems. A Test for the $\Delta(\mathrm{SV})$ model is excluded as $\Delta(\mathrm{SV})$ is not a return. ${ }^{14}$ Due to the high p-values, the null hypothesis of no unexplained returns on average needs to be rejected within all proposed models. Hence, no factor model "fully" explains returns on the German stock market.

Considering the estimates of the factor risk premiums in Table 6, the market risk factor premium RMRF is not significantly different from zero. This result is consistent with other studies on the German capital market (see for example Elsas, El-Shaer, and Theissen (2003)). As shown in Table 4, the realized market risk premium over the observation period is $0.293 \%$ per month with a standard deviation of $5.876 \%$. Hence, relying on the moments of the empirical distribution over our observation period, the probability of a normally distributed random variable to be negative (i.e. $r_{M}<r_{f}$ ) is about $48 \%$ $\left(r_{M}\right.$ denotes the market return and $r_{f}$ is the risk free rate). Under such conditions, the power of typical asset pricing test approaches is fairly low, see Elsas, El-Shaer, and Theissen (2003) and Pettengill, Sundaram, and Mathur (1995).

Table 6 further shows that the estimates of the risk premia for SMB, HML and the default risk factor DEF are significantly different from zero. The significant premiums of SMB and HML are almost unchanged, if the default risk factor is added, indicating that the book-to-market effect is not primarily

\footnotetext{
$\overline{13}$ Please refer to the appendix.

14 See e.g. Cochrane (2005, p. 243f).
} 
Table 5

Time-series Estimates of Factor Sensitivities and the Test on the Intercepts

The table shows estimated factor sensitivities from a time-series regression of the test asset portfolio returns on a varying set of factors. Panel A and Panel B compare two models which contain the Fama/French factors and one particular default factor. $\Delta(\mathrm{SV})$ is the change in aggregate default risk, as suggested by Vassalou and Xing (2004), while DEF is the excess return of a portfolio of firms with low default risk over a portfolio of firms with high default risk. The values are computed using the two-stage GMM approach described in Section 2.3 and the appendix, simultaneously estimating timeseries and cross-sectional regressions. The estimated factor risk premia from the crosssectional regressions are shown in Table 6. The sample period is 1990:7 to 2006:6. For the two different models we use the same test assets which have a $2 \times 2 \times 3$ structure, that is, they are independently sorted on firm size, book-to-market, and distance-to-default. tvalues are calculated with GMM using the Newey-West estimator for the spectral density matrix. The number of maximum lags is $l=3$. Panel $\mathrm{C}$ compares the market model, the Fama/French three factor model and the two models containing the default factors. The results of a Wald test are displayed in the row "Wald" with $H_{0}: \alpha_{1}=\ldots=\alpha_{N}=0$, where $\alpha_{i}$ is the intercept of portfolio i's regression. $E_{i}(\alpha)$ is the mean of $\alpha_{1} \ldots \alpha_{N}$. ${ }^{*},{ }^{* *}$ and ${ }^{* * *}$ denotes significance at the 10\%-, 5\%- and 1\%-level, respectively.

Panel A: Factor Sensitivities and T-stats of the DEF model

\begin{tabular}{lll|cccccccc}
\hline \hline \multicolumn{3}{c}{ Portfolio } & \multicolumn{2}{c}{$\beta_{R M R F}$} & \multicolumn{2}{c}{$\beta_{S M B}$} & \multicolumn{2}{c}{$\beta_{H M L}$} & \multicolumn{2}{c}{$\beta_{D E F}$} \\
\hline DD & SIZE & BM & Coef. & t-value & Coef. & t-value & Coef. & t-value & Coef. & t-value \\
\hline Low & Small & Low & 0.91 & $\left(15.04^{* * *}\right)$ & 1.04 & $\left(12.31^{* * *}\right)$ & 0.04 & $(0.52)$ & -0.40 & $\left(-5.66^{* * *}\right)$ \\
Low & Small & High & 1.04 & $\left(27.58^{* * *}\right)$ & 0.98 & $\left(17.79^{* * *}\right)$ & 0.55 & $\left(12.09^{* * *}\right)$ & -0.11 & $\left(-2.46^{* *}\right)$ \\
Low & Big & Low & 0.86 & $\left(7.90^{* * *}\right)$ & -0.16 & $(-0.82)$ & -0.24 & $\left(-2.26^{* *}\right)$ & -1.41 & $\left(-8.21^{* * *}\right)$ \\
Low & Big & High & 0.79 & $\left(8.47^{* * *}\right)$ & 0.32 & $\left(2.22^{* *}\right)$ & 0.34 & $\left(2.75^{* * *}\right)$ & -0.94 & $\left(-6.06^{* * *}\right)$ \\
Med & Small & Low & 0.86 & $\left(15.93^{* * *}\right)$ & 0.85 & $\left(9.63^{* * *}\right)$ & -0.08 & $(-0.77)$ & -0.16 & $\left(-2.00^{* *}\right)$ \\
Med & Small & High & 0.85 & $\left(16.24^{* * *}\right)$ & 0.79 & $\left(10.11^{* * *}\right)$ & 0.47 & $\left(9.07^{* * *}\right)$ & -0.13 & $\left(-2.53^{* *}\right)$ \\
Med & Big & Low & 1.08 & $\left(18.83^{* * *}\right)$ & -0.07 & $(-0.80)$ & -0.21 & $\left(-2.74^{* * *}\right)$ & -0.15 & $\left(-1.90^{*}\right)$ \\
Med & Big & High & 0.93 & $\left(12.31^{* * *}\right)$ & 0.01 & $(0.12)$ & 0.23 & $\left(1.78^{*}\right)$ & -0.15 & $(-1.39)$ \\
High & Small & Low & 0.97 & $\left(11.64^{* * *}\right)$ & 1.18 & $\left(8.85^{* * *}\right)$ & -0.06 & $(-0.41)$ & 0.47 & $\left(3.19^{* * *}\right)$ \\
High & Small & High & 0.88 & $\left(10.94^{* * *}\right)$ & 1.09 & $\left(8.32^{* * *}\right)$ & 0.49 & $\left(4.91^{* * *}\right)$ & 0.39 & $\left(2.99^{* * *}\right)$ \\
High & Big & Low & 0.91 & $\left(26.17^{* * *}\right)$ & -0.02 & $(-0.33)$ & -0.06 & $(-1.25)$ & 0.10 & $\left(2.02^{* *}\right)$ \\
High & Big & High & 0.83 & $\left(14.81^{* * *}\right)$ & -0.06 & $(-0.87)$ & 0.32 & $\left(3.72^{* * *}\right)$ & 0.18 & $\left(3.01^{* * *}\right)$ \\
\hline \hline
\end{tabular}

Panel B: Factor Sensitivities and T-stats of the $\Delta(\mathrm{SV})$ model

\begin{tabular}{lll|cccccccc}
\hline \hline \multicolumn{3}{c}{ Portfolio } & \multicolumn{3}{c}{$\beta_{R M R F}$} & \multicolumn{3}{c}{$\beta_{S M B}$} & \multicolumn{3}{c}{$\beta_{H M L}$} & \multicolumn{2}{c}{$\beta_{\Delta(\mathrm{SV})}$} \\
\hline DD & SIZE & BM & Coef. & t-value & Coef. & t-value & Coef. & t-value & Coef. & t-value \\
\hline Low & Small & Low & 1.00 & $\left(12.85^{* * *}\right)$ & 1.25 & $\left(12.91^{* * *}\right)$ & 0.14 & $(1.62)$ & -0.41 & $(-0.60)$ \\
Low & Small & High & 1.01 & $\left(23.02^{* * *}\right)$ & 0.99 & $\left(17.53^{* * *}\right)$ & 0.56 & $\left(11.50^{* * *}\right)$ & 0.78 & $\left(1.91^{*}\right)$ \\
Low & Big & Low & 1.12 & $\left(8.09^{* * *}\right)$ & 0.52 & $\left(2.20^{* *}\right)$ & 0.09 & $(0.50)$ & -0.44 & $(-0.32)$ \\
Low & Big & High & 0.89 & $\left(7.49^{* * *}\right)$ & 0.70 & $\left(4.08^{* * *}\right)$ & 0.53 & $\left(3.47^{* * *}\right)$ & 0.83 & $(0.64)$ \\
Med & Small & Low & 0.84 & $\left(12.18^{* * *}\right)$ & 0.87 & $\left(8.51^{* * *}\right)$ & -0.06 & $(-0.63)$ & 0.82 & $\left(1.71^{*}\right)$ \\
Med & Small & High & 0.94 & $\left(16.28^{* * *}\right)$ & 0.92 & $\left(11.93^{* * *}\right)$ & 0.53 & $\left(9.85^{* * *}\right)$ & -1.18 & $\left(-2.85^{* * *}\right)$ \\
Med & Big & Low & 1.06 & $\left(16.46^{* * *}\right)$ & -0.04 & $(-0.51)$ & -0.20 & $\left(-2.66^{* * *}\right)$ & 0.68 & $(1.36)$ \\
Med & Big & High & 0.87 & $\left(10.72^{* * *}\right)$ & -0.01 & $(-0.14)$ & 0.23 & $(1.57)$ & 1.41 & $\left(2.41^{* *}\right)$ \\
High & Small & Low & 0.87 & $\left(5.91^{* * *}\right)$ & 0.94 & $\left(6.07^{* * *}\right)$ & -0.18 & $(-1.07)$ & 0.41 & $(0.36)$ \\
High & Small & High & 0.83 & $\left(9.98^{* * *}\right)$ & 0.92 & $\left(7.21^{* * *}\right)$ & 0.41 & $\left(5.12^{* * *}\right)$ & -0.25 & $(-0.22)$ \\
High & Big & Low & 0.91 & $\left(23.43^{* * *}\right)$ & -0.04 & $(-0.79)$ & -0.08 & $(-1.54)$ & -0.34 & $(-1.12)$ \\
High & Big & High & 0.83 & $\left(12.98^{* * *}\right)$ & -0.11 & $(-1.48)$ & 0.29 & $\left(3.10^{* * *}\right)$ & -0.54 & $(-1.12)$ \\
\hline \hline
\end{tabular}

Panel C: Wald Tests on the Joint Significance of Intercepts

\begin{tabular}{ccccccccc}
\hline \hline & \multicolumn{2}{c}{ CAPM } & \multicolumn{2}{c}{ Fama French } & \multicolumn{2}{c}{ DEF model } & \multicolumn{2}{c}{$\Delta(\mathrm{SV})$ model } \\
\hline Wald & 30.522 & $\left(0.003^{* * *}\right)$ & 35.138 & $\left(0.001^{* * *}\right)$ & 30.422 & $\left(0.004^{* * *}\right)$ & - & - \\
$E_{i}(\alpha)$ & -0.173 & - & -0.003 & - & 0.124 & - & 0.002 & - \\
\hline \hline
\end{tabular}


Table 6

Cross-sectional Estimates of Factor Risk Premia

The table compares the CAPM, the Fama/French three factor model and two models which contain the Fama/French factors and one particular variant of the default factor. The values are computed by a two-stage GMM approach using time-series and crosssectional information at the same time. In this table only the cross-sectional results are displayed, time-series results can be found in Table 5. The sample period is 1990:7 to 2006:6. For the four different models we use the same test assets, that have a $2 \times 2$ x 3 structure, sorted on firm size, book-to-market, and the firms' distance-to-default. tvalues are calculated with GMM using the Newey-West estimator for the spectral density matrix. The number of maximum lags is $l=3 .{ }^{*}, * *$ and $* * *$ denotes significance at the $10 \%-, 5 \%$ - and $1 \%$-level, respectively.

\begin{tabular}{|c|c|c|c|c|c|}
\hline & & CAPM & Fama/French & DEF model & $\Delta(\mathrm{SV})$ model \\
\hline & variable & coef(t-val) & $\operatorname{coef}(\mathrm{t}-\mathrm{val})$ & coef(t-val) & coef(t-val) \\
\hline \multirow{10}{*}{ 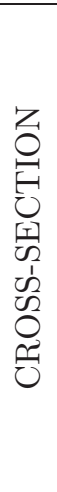 } & \multirow[t]{2}{*}{$\lambda_{R M R F}$} & 0.066 & 0.326 & 0.473 & 0.285 \\
\hline & & (0.139) & $(0.737)$ & $(1.085)$ & $(0.642)$ \\
\hline & \multirow[t]{2}{*}{$\lambda_{S M B}$} & \multirow[t]{2}{*}{ - } & -0.743 & -0.788 & -0.730 \\
\hline & & & $\left(-2.501^{* *}\right)$ & $\left(-2.656^{* * *}\right)$ & $(-2.450 * *)$ \\
\hline & \multirow[t]{2}{*}{$\lambda_{H M L}$} & \multirow[t]{2}{*}{ - } & 0.831 & 1.007 & 0.863 \\
\hline & & & $\left(1.909^{*}\right)$ & $\left(2.303^{* *}\right)$ & $\left(1.964^{* *}\right)$ \\
\hline & \multirow[t]{2}{*}{$\lambda_{D E F}$} & \multirow[t]{2}{*}{-} & \multirow[t]{2}{*}{ - } & 0.713 & - \\
\hline & & & & $\left(2.271^{* *}\right)$ & \\
\hline & \multirow[t]{2}{*}{$\lambda_{\Delta(\mathrm{SV})}$} & \multirow[t]{2}{*}{ - } & \multirow[t]{2}{*}{ - } & \multirow[t]{2}{*}{-} & 0.138 \\
\hline & & & & & $(0.982)$ \\
\hline
\end{tabular}

driven by correlation with default risk, contrary to the suggestion and findings of Ferguson and Shockley (2003).

\subsection{Factors Determining the Pricing Kernel}

In what follows, we use the GMM discount factor model of section 2.3 with the moment conditions of equation (14) in the appendix to infer factors determining the pricing kernel. This serves as a robustness test for the results from the times-series/cross-section analysis in the preceding section. Also, we report estimation results for the overall period 1990:7 to 2006:6 and the subperiods 1990:7 to 2001:6 and 2001:7 to 2006:6, to test the robustness of our results. The end of the first subperiod, that is June 2001 is located after the Internet bubble ${ }^{15}$ which takes place from early 1998 to the end of 2000 and before the crash of $9 / 11$. We use these two subperiods as Figure 1 implies a potential structural break between the years 2000 and 2002 regarding the size, the BM and perhaps the DEF effect. ${ }^{16}$

Focusing on the overall period 1990:7 to 2006:6 first, the results in Panel A of Table 7 show that DEF is systematically priced in the German capital market. For this factor, both the coefficient estimate on the pricing kernel weight

\footnotetext{
$\overline{15}$ The Internet bubble and its timing was analysed by Ofek and Richardson (2003).

${ }^{16}$ We also tried the period limits 2000:6 and 2002:6 but the results for both subperiods do not change qualitatively.
} 
Table 7

Stochastic Discount Factor Test

This table reports the results of the stochastic discount factor and cross-sectional asset pricing test over three time horizons (1990:7 to 2006:6, 1990:7 to 2002:6 and 2002:7 to 2006:6). The stochastic discount factor estimates are computed by a two-stage GMM model as outlined by Cochrane (2005). The factor columns (RMRF, SMB, HML, DEF and $\Delta(\mathrm{SV})$ ) contain the SDF coefficient estimates ("coef"), and in brackets the tstatistics. The rows labeled "prem" show the estimated factor risk premia. Again tstatistics are reported in brackets. The column labeled $J$-test shows for each time horizon the results of a $J$ test for overidentifying restrictions. We report the test statistic and the corresponding $\mathrm{p}$-value (in parentheses). The premiums are measured in percent whereas the SDF coefficient estimates are presented $\mathrm{x}$ 10,000. $\mathrm{t}$-values are calculated with GMM using the Newey-West estimator for the spectral density matrix. The number of maximum lags is $l=3 .{ }^{*}, * *$ and $* * *$ denotes significance at the $10 \%-, 5 \%$ - and $1 \%$-level, respectively.

\begin{tabular}{|c|c|c|c|c|c|c|}
\hline & RMRF & SMB & HML & $\mathrm{DEF}$ & $\Delta(\mathrm{SV})$ & $J$-test \\
\hline coef & $1.89(1.51)$ & - & - & - & - & $17.64\left(0.09^{*}\right)$ \\
\hline prem & $0.07(0.14)$ & - & - & - & - & - \\
\hline coef & $1.23(0.73)$ & $-6.21\left(-2.36^{* *}\right)$ & $3.82(1.62)$ & - & - & $11.62(0.24)$ \\
\hline prem & $0.33(0.74)$ & $-0.74\left(-2.50^{* *}\right)$ & $0.83\left(1.91^{*}\right)$ & - & - & - \\
\hline coef & $1.69(1.03)$ & $-4.64\left(-1.77^{*}\right)$ & $4.49\left(1.96^{* *}\right)$ & $4.52\left(2.34^{* *}\right)$ & - & $8.67(0.37)$ \\
\hline prem & $0.47(1.09)$ & $-0.79\left(-2.66^{* * *}\right)$ & $1.01\left(2.30^{* *}\right)$ & $0.71\left(2.27^{* *}\right)$ & - & - \\
\hline coef & $3.11(0.81)$ & $-4.18(-0.87)$ & $4.68\left(1.68^{*}\right)$ & - & $-24.34(-0.48)$ & $10.16(0.25)$ \\
\hline prem & $0.28(0.64)$ & $-0.73\left(-2.45^{* *}\right)$ & $0.86\left(1.96^{* *}\right)$ & - & $0.14(0.98)$ & - \\
\hline
\end{tabular}

Panel B: 1990:7 to 2001:6

\begin{tabular}{llllll|l}
\hline \hline & RMRF & SMB & HML & DEF & $\Delta(\mathrm{SV})$ & $J$-test \\
\hline coef & $2.29(1.39)$ & - & - & - & - & $15.82(0.15)$ \\
prem & $-0.09(-0.18)$ & - & - & - & - & - \\
coef & $-2.46(-0.94)$ & $-12.78\left(-3.80^{* * *}\right)$ & $-0.82(-0.35)$ & - & - & $9.92(0.36)$ \\
prem & $0.33(0.67)$ & $-0.95\left(-2.85^{* * *}\right)$ & $0.19(0.37)$ & - & - & - \\
coef & $-1.37(-0.50)$ & $-9.91\left(-2.71^{* * *}\right)$ & $0.72(0.33)$ & $4.80\left(2.21^{* *}\right)$ & - & $7.16(0.52)$ \\
prem & $0.47(0.98)$ & $-0.96\left(-2.87^{* * *}\right)$ & $0.34(0.66)$ & $1.06\left(2.81^{* * *}\right)$ & - & - \\
coef & $0.05(0.01)$ & $-8.47(-1.48)$ & $-0.10(-0.04)$ & - & $-55.64(-0.54)$ & $9.49(0.30)$ \\
prem & $0.53(1.09)$ & $-0.87\left(-2.53^{* *}\right)$ & $-0.05(-0.08)$ & - & $-0.15(-1.47)$ & - \\
\hline \hline
\end{tabular}

Panel C: 2001:7 to 2006:6

\begin{tabular}{llllll|l}
\hline \hline & RMRF & SMB & HML & DEF & $\Delta(\mathrm{SV})$ & $J$-test \\
\hline coef & $1.15(0.66)$ & - & - & - & - & $12.06(0.36)$ \\
prem & $0.45(0.45)$ & - & - & - & - & - \\
coef & $3.37\left(1.66^{*}\right)$ & $1.02(0.32)$ & $21.85\left(3.86^{* * *}\right)$ & - & - & $10.17(0.34)$ \\
prem & $0.40(0.43)$ & $-0.41(-0.65)$ & $1.59\left(1.96^{* *}\right)$ & - & - & - \\
coef & $3.92\left(1.88^{*}\right)$ & $2.74(0.78)$ & $24.27\left(4.02^{* * *}\right)$ & $3.35(1.26)$ & - & $9.32(0.32)$ \\
prem & $0.48(0.52)$ & $-0.45(-0.71)$ & $1.73\left(2.21^{* *}\right)$ & $0.11(0.19)$ & - & - \\
coef & $11.91\left(1.77^{*}\right)$ & $5.34(0.96)$ & $28.89\left(3.97^{* * *}\right)$ & - & $-80.57(-1.34)$ & $9.13(0.33)$ \\
prem & $0.47(0.49)$ & $-0.55(-0.88)$ & $1.79\left(2.12^{* *}\right)$ & - & $-0.05(-0.17)$ & - \\
\hline \hline
\end{tabular}

(coef) and the risk premium estimate from the combined time-series / crosssectional-regression risk premium (prem) are statistically different from zero. In contrast, the market risk factor and the default risk factor $\Delta(\mathrm{SV})$ suggested by Vassalou and Xing (2004) are insignificant in all cases according to both tests. BM has a significant risk premium, but significantly contributes to the pricing kernel only in two of three cases. The premium is in all models posi- 
tive, in line with Figure 1 and Table 4. Finally, the SIZE effect is statistically significant, but the risk premium is actually negative.

A different result can be found for the two subperiods 1990:7 to 2001:6 (Panel B) and 2001:7 to 2006:6 (Panel C). The former subperiod of Panel B shows again a significant DEF factor and an insignificant market and $\Delta(\mathrm{SV})$ factor compared to the overall period. In contrast, the SIZE effect is mostly significant with a negative risk premium and the BM effect is insignificant over all models and tests. The latter subperiod illustrated in Panel $\mathrm{C}$ reveals a highly significant BM effect with positive risk premium and an insignificant size effect and default proxies. The market factor shows a slight positive effect in the SDF test. Those results are in line with our earlier suggestions.

Finally, note that the estimated risk premium of DEF for the overall period ( $0.71 \%$ per month) and the factor contribution to the pricing kernel (4.52) indicate that equity returns are decreasing for firms more likely to default. This result corresponds e.g. to Dichev (1998) and other studies in the U.S., but contradicts the results by Vassalou and Xing (2004).

\section{Financial System Comparison, and Bank Dependence as Stock Return Determinant}

\subsection{Default Risk Factors for the U.S. Market}

The preceding section has shown that the Vassalou and Xing (2004) default risk factor is not priced in the German capital market, and we actually find that equity returns decrease with higher default risk of firms. As a first step to understand these differences in results for the two countries, we replicate the study by Vassalou and Xing (2004) for the U.S. market and test whether the design of the factor matters for the U.S. market as well.We use the distances-to-default provided by Vassalou and Xing (2004), and match these data with firms' accounting information from Compustat, and market capitalization from CRSP, to construct the excess return DEF factor for the U.S. market. 17

The test portfolios for the U.S. market are constructed using a $3 \times 3 \times 3$ sort of size, book-to-market and default risk, to establish comparability with previous results. The results of the asset pricing tests are shown in Table 8.

Panel B shows the results of the $\Delta(\mathrm{SV})$ model used by Vassalou and Xing (2004) and replicates their results. The coefficient on $\Delta(\mathrm{SV})$ in the stochas-

\footnotetext{
${ }^{17}$ Since the DD estimates for the U.S. are provided by Vassalou and Xing (2004), the sample period is now January 1971 to December 1999. The Fama/French factors and the risk-free rates are downloaded from the Kenneth R. French Homepage.
} 
Table 8

$\mathrm{DEF}$ and $\Delta(\mathrm{SV})$ on the U.S. Market

This table provides stochastic discount factor and cross-sectional asset pricing test for the U.S. market over the period 1971-1999. DD estimates are from Vassalou and Xing (2004). Panel A shows the results of the Fama/French model augmented by our micking factor portfolio "DEF", Panel B shows the results of the Fama/French model augmented by " $\Delta(\mathrm{SV})$ ", and Panel C reports the results of the Fama/French model augmented by both "DEF" and " $\Delta(\mathrm{SV})$ ". The factor columns (RMRF, SMB, HML, DEF and $\Delta(\mathrm{SV})$ ) contain the SDF coefficient estimates ("coefficient") with t-values in parentheses. Rows labeled "premium" show the estimated factor risk premia. The column labeled J-test shows the test statistic and the corresponding p-value of a $J$ test for overidentifying restrictions. Factor premia are measured in percent, whereas the SDF coefficient estimates are presented x 10,000. t-values are calculated with GMM using the Newey-West estimator for the spectral density matrix, where the number of lags is $l=3$. *** and *** denotes significance at the $10 \%$-, $5 \%$ - and $1 \%$-level, respectively.

Panel A: DEF

\begin{tabular}{|c|c|c|c|c|c|c|c|}
\hline & RMRF & SMB & HML & DEF & $\Delta(\mathrm{SV})$ & & $J$-test \\
\hline coefficient & 10.358 & 6.791 & 13.098 & 15.709 & - & Statistic & 30.087 \\
\hline t-value & $\left(6.348^{* * *}\right)$ & $\left(2.532^{* *}\right)$ & $\left(5.692^{* * *}\right)$ & $\left(5.337^{* * *}\right)$ & - & p-value & $(0.147)$ \\
\hline premium & 0.648 & -0.012 & 0.372 & 0.250 & - & - & - \\
\hline t-value & $\left(2.514^{* *}\right)$ & $(-0.071)$ & $\left(2.034^{* *}\right)$ & $\left(1.655^{*}\right)$ & - & - & - \\
\hline
\end{tabular}

Panel B: $\Delta(\mathrm{SV})$

\begin{tabular}{cccccccc}
\hline \hline & RMRF & SMB & HML & DEF & $\Delta(\mathrm{SV})$ & $J$-test \\
\hline coefficient & 13.809 & 11.043 & 10.867 & - & -66.928 & Statistic & 30.123 \\
t-value & $\left(6.445^{* * *}\right)$ & $\left(3.497^{* * *}\right)$ & $\left(4.264^{* * *}\right)$ & - & $\left(-4.014^{* * *}\right)$ & p-value & $(0.146)$ \\
premium & 0.538 & 0.043 & 0.299 & - & -0.417 & - & - \\
t-value & $\left(2.078^{* *}\right)$ & $(0.257)$ & $(1.642)$ & - & $\left(-3.159^{* * *}\right)$ & - & - \\
\hline \hline
\end{tabular}

Panel C: All factor model

\begin{tabular}{|c|c|c|c|c|c|c|c|}
\hline & RMRF & SMB & HML & DEF & $\Delta(\mathrm{SV})$ & & $J$-test \\
\hline coefficient & 11.183 & 7.995 & 12.875 & 14.737 & -9.343 & Statistic & 29.965 \\
\hline t-value & $\left(5.655^{* * *}\right)$ & $\left(2.531^{* *}\right)$ & $\left(5.570^{* * *}\right)$ & $\left(3.871^{* * *}\right)$ & $(-0.522)$ & p-value & (0.119) \\
\hline premium & 0.645 & -0.009 & 0.369 & 0.246 & 0.028 & - & - \\
\hline t-value & $\left(2.505^{* *}\right)$ & $(-0.056)$ & $\left(2.008^{* *}\right)$ & $\left(1.650^{*}\right)$ & $(0.201)$ & - & - \\
\hline
\end{tabular}

tic discount factor test is statistically highly significant from zero, as is the risk premium estimate from the joint GMM time-series / cross section-regression. ${ }^{18}$

Panel A of Table 8 illustrates, however, that the default risk factor constructed as an excess portfolio return of firms with high DD over firms with low DD also explains systematically stock returns in the U.S. Similar to our results for the German capital market, the coefficient on DEF in the stochastic discount factor test is significantly different from zero and positive. Hence, also in the U.S., firms with higher DD have on average higher returns than firms with low DD. Although both $\Delta(\mathrm{SV})$ and DEF serve to control for firms' default risk, the two factors significantly contribute to price assets in the U.S., but in contradictory directions.

\footnotetext{
${ }^{18}$ The numerical differences from the results reported by Vassalou and Xing (2004) arises because we have not been able to fully reconstruct Vassalou/Xing's sample. Using the matched Compustat and CRSP database leads to roughly $10 \%$ less sample firms than in their data.
} 
This raises the question, which factor better approximates a systematic default risk component. On theoretical grounds, arguably one might prefer the DEF-factor because it is a direct measure of the market price of systematic default risk, while $\Delta(\mathrm{SV})$ merely reflects the change in the overall market average PD. Empirically, it is a priori unclear which factor construction to prefer. To compare the two measures directly, Panel $\mathrm{C}$ of Table 8 shows estimation results from including both default risk factors simultaneously into the regression. The result is striking $-\Delta(\mathrm{SV})$ looses its explanatory power, while DEF remains highly significant in the SDF test. Note that this is not due to multi-collinearity since the test for overidentifying restrictions (J-test) implies the model is not misspecified, under multi-collinearity both factors should become insignificant, and the correlation between DEF and $\Delta(\mathrm{SV})$ is only -0.197 .

Hence, default risk is actually priced in the U.S. market, but the effect is contrary to what Vassalou and Xing (2004) have reported - firms with higher default risk have on average lower returns than firms with lower default risks. The opposite effect reported by Vassalou and Xing (2004) is not robust since their factor looses its explanatory power when using the DEF factor to control for non-diversifiable default risk. As a second result, the impact of default risk on stock returns is the same for the German and the U.S. stock market, despite the structural differences between the two financial systems.

\subsection{Bank Dependence and Default Risk Sensitivity Determinants}

To further examine the question, whether the impact of default risk on equity returns depends on the financial system firms operate in, we test in this section whether equity returns are affected by corporate financing characteristics attributable to the financial system. We focus on the role of bank debt, since the relevance of bank debt for corporate finance constitutes one major difference between the German and the U.S. financial system, and at least theoretically, banks might play a significant role as an active corporate governance mechanism.

The theory of financial intermediation suggests that in particular banks are special in acquiring and processing (private) information about firms. Information acquisition and repeated interaction can then lead to relationship lending, where the information privilege of the relationship lender ties the firm to the bank and (in turn) allows an intertemporal design of loan contracts (see Boot (2000) for an overview). If relationship lending does indeed mitigate problems due to asymmetric information between firm stakeholders, then one should expect that the relevance of bank debt mitigates premia inherent in stock returns that are due to these factors. Hence, our hypothesis is that firms that are more likely to have a relationship lender will be less affected by systematic default risk, all else equal. Elsas (2005) provides evidence that relationship 
lender can empirically be best identified by the share of bank debt of a firm's capital structure. We use this measure to test whether a firm's degree of bank dependence affects the default factor sensitivity.

The variable BANKDEBT correspondingly serves as the proxy for the bank dependence of firms, calculated as the average bank debt over each 3-year period, divided by the average book value of total assets in that period. Default risk sensitivities are estimated for five successive (non-overlapping) 3-year periods starting in January 1991 (labeled $\beta_{D E F}$ ). These sensitivities are then regressed on a set of explanatory variables, including BANKDEBT. ${ }^{19}$

To avoid omitted variables biases, the empirical model needs to take further theoretical sensitivity determinants into account. First, one should expect that a firm's sensitivity to the non-diversifiable market default risk is related to the individual default risk of the firm. Note, however that there need not be a one-to-one correspondence, since only the systematic part of default risk is reflected in asset prices, and this component is not necessarily proportional to individual default risk. We use the average distance-to-default of a firm over the 3-year period (and its squared value to allow for nonlinear effects) as the corresponding regressor.

Second, recent theoretical work by Carlson, Fisher, and Giammarino (2004) and Garlappi and Yan (2008) suggests that the book-to-market and size effect are related to default risk due to the option-like characteristic of equity and the existence of absolute-priority-deviations in firm financial distress. Although our empirical results do not suggest that the size and in particular the strong book-to-market effect depend on default risk, we test and control for this effect by including the average book-to-market ratio in the regression as a potential determinant of default factor sensitivities.

Finally, we use some standard control variables to control for general firm heterogeneity in the cross-section of our sample. Firm size is measured by the natural logarithm of firm market value of equity (SIZE), profitability is measured by the ratio of EBIT over the book value of total asset (ROA), firm leverage (i.e. the part not captured by the market value based leverage inherent in the distance-to-default) is measured by the ratio of total liabilities over book value of total assets (LIABILITIES). The regressions are conducted as fixedeffect panel regressions, with firm specific and time dummy variables. The time dummy variables control for all macro-economic factors potentially affecting sensitivities (like the interest rate level etc.), while the firm-specific effects control for all time-invariant firm characteristics, like the industry affiliation.

Table 9 provides some descriptive statistics on the variables of primary interest used in the regression analysis. Panel A of Table 9 shows that the

\footnotetext{
$\overline{19}$ The sensitivity estimates are taken from time-series regressions of firms' returns on the DEF model (including the other Fama/French factors). This leads to at most 5 observations for each firm and constitutes a panel data set.
} 
Table 9

Descriptive Statistics on Bank Debt Financing and Default Risk Sensitivities

The table reports descriptive statistics on firms' default risk factor sensitivities $\beta_{D E F}$. These sensitivities are calculated by 3-year time-series regressions of stock returns on the four factors RMRF, SMB, HML, and DEF. A maximum number of five observations for each firm using the periods 1991:1 to $1993: 12$, 1994:1 to $1996: 12$... 2003:1 to 2005:12 is possible. Panel A also shows summary statistics on BANKDEBT, calculated as the average bank debt over each 3-year period, divided by the average book value of total assets in that period. Panel B shows a cross-tabulation of default factor sensitivities and groups of firms sorted by their distance-to-default (DD), firms' market value of equity (SIZE), and the book-to-market ratio (BM). t-statistics are in parentheses. *,** and *** denotes significance at the 10\%-, 5\%- and 1\%-level, respectively.

Panel A: $\beta_{\mathrm{DEF}}$ and BANKDEBT

\begin{tabular}{lccccc}
\hline \hline variable & mean & t-stat & std & $\min$ & $\max$ \\
\hline$\beta_{\text {DEF }}$ & -0.1188 & $\left(-5.8408^{* * *}\right)$ & 0.7517 & -3.0000 & 3.0000 \\
BANKDEBT & 0.1917 & - & 0.1597 & 0.0000 & 0.8013 \\
\hline \hline
\end{tabular}

Panel B: mean $\beta_{\mathrm{DEF}}$ of DD, SIZE and BM portfolios

\begin{tabular}{|c|c|c|c|c|}
\hline \multirow{3}{*}{$\hat{\mathrm{A}}$} & & LowDD & MedDD & HighDD \\
\hline & mean & -0.2085 & -0.1477 & -0.0002 \\
\hline & t-stat & $\left(-4.6867^{* * *}\right)$ & $\left(-4.6479^{* * *}\right)$ & $(-0.0080)$ \\
\hline & & Small & Big & \\
\hline \multirow{3}{*}{ 空 } & mean & -0.1609 & -0.0767 & \\
\hline & t-stat & $\left(-4.7090^{* * *}\right)$ & $\left(-3.4882^{* * *}\right)$ & \\
\hline & & ${ }_{\text {Low }}$ & HighBM & \\
\hline \multirow{2}{*}{$\sum_{m}$} & mean & -0.0945 & -0.1430 & \\
\hline & t-stat & $\left(-3.2977^{* * *}\right)$ & $\left(-4.9569^{* * *}\right)$ & \\
\hline
\end{tabular}

average and median of default factor sensitivities is negative with a mean of about -0.12. There are frequent sensitivity estimates of larger magnitude, with distinctively positive or negative values. ${ }^{20}$ The table also shows the debt structure of German listed firms to be heterogenous. Still, bank debt is quite generally important for corporate finance with an average bank debt ratio of about $19 \%$ and a standard deviation of about $16 \% .{ }^{21}$ The high relevance of bank debt financing illustrates why the German financial system often serves as the prime example for a bank-based financial system.

Panel B of Table 9 shows that small firms, value-firms and firms with a high probability of default (corresponding to a low DD) typically load negative on the default risk factor. Recall that this factor is constructed as the excess return of firms with low $\mathrm{PD}$ over firms with high $\mathrm{PD}$ and has a positive premium. The average sensitivity of -0.2085 of firms with a low DD illustrates

\footnotetext{
${ }^{20}$ We winsorize the sensitivity estimates exceeding an absolute value of 3 to avoid estimation problems due to outliers.

${ }^{21}$ The information on bank debt is taken from the Hoppenstedt German firm database, since it is not explicitly shown in Worldscope.
} 
Table 10

Factor Sensitivity Regressions

The table reports estimation results from two regressions of firms' default factor sensitivities on a set of potential determinants. DD denotes distance-to-default, SIZE is the natural logarithm of a firm's average equity market value of each time period, BM denotes the ratio of book value of equity over market value of equity, ROA denotes return on assets measured as the ratio of EBIT over the book value of total assets. BANKDEBT describes the ratio of bank debt divided by total assets, and LIABILITIES is the ratio of total liabilities over total assets. All ratios are averaged over the time period. Both regressions differ in the choice of dependent variables. The model labeled by "FE" uses the default factor sensitivity as dependent variable whereas the model labeled by "FE $a b s "$ uses the absolute default factor sensitivity. The default factor sensitivities are calculated by non-overlapping 3-year time-series regressions of stock returns on the four factors RMRF, SMB, HML and DEF. DD greater than 30 and absolute values of sensitivities in excess of 3 are winsorized. The model includes firm fixed-effects and dummy variables indicating the time period of the observation. The F-test in the last row of the table tests the null that all year dummy coefficients equal zero. Fixed-effects are significant throughout (not reported), t-statistics are in parentheses. ${ }^{*}, * *$ and $* * *$ denotes significance at the $10 \%$-, 5\%- and 1\%-level, respectively.

Fixed Effects Regressions

\begin{tabular}{|c|c|c|c|c|}
\hline & \multicolumn{2}{|c|}{$\mathrm{FE}$} & \multicolumn{2}{|c|}{$\mathrm{FE}_{a b s}$} \\
\hline & coef. & t-value & coef. & t-value \\
\hline INTERCEPT & -1.061 & $\left(-3.84^{* * *}\right)$ & 1.216 & $\left(6.76^{* * *}\right)$ \\
\hline $\mathrm{DD}$ & 0.055 & $\left(3.27^{* * *}\right)$ & -0.362 & $(-3.30 * * *)$ \\
\hline $\mathrm{DD}^{2}$ & -0.001 & $\left(-1.80^{*}\right)$ & 0.001 & $\left(2.50^{* *}\right)$ \\
\hline LIABILITIES & -0.167 & $(-0.05)$ & -0.257 & $(-1.07)$ \\
\hline BANKDEBT & 2.001 & $\left(3.07^{* * *}\right)$ & -1.777 & $\left(-4.18^{* * *}\right)$ \\
\hline BANKDEBTxLIABILITIES & -1.958 & $\left(-2.36^{* *}\right)$ & 2.416 & $\left(4.49^{* * *}\right)$ \\
\hline $\mathrm{ROA}$ & -0.274 & $(-1.35)$ & 0.005 & $(0.03)$ \\
\hline SIZE & 0.063 & $(1.29)$ & -0.057 & $\left(-1.79^{*}\right)$ \\
\hline$\frac{\mathrm{BM}}{\mathrm{F}-\mathrm{T} \text { - }}-\mathbf{-}-\mathbf{-}-\mathbf{-}-\mathbf{-}-\mathbf{-}$ & $\begin{array}{l}0.093 \\
\mathrm{p}-\mathrm{val}<0.0\end{array}$ & $\left(2.05^{* *}\right)$ & $\begin{array}{l}\mathrm{p}-\mathrm{val}<0.064 \\
-0.064\end{array}$ & $\left(-2.18^{* *}\right)$ \\
\hline$R^{2}$ & 0.059 & - & 0.090 & - \\
\hline
\end{tabular}

our result from the preceding sections, that average returns are lower for firms with higher default risk.

The regression results of default risk sensitivities on the set of explanatory variables are shown in Table 10. We report two specifications in Columns 2 (labeled by "FE") and 3 (labeled by "FEabs"), where we use sensitivities and absolute sensitivities as the dependent variable, respectively. The regression of absolute sensitivities focuses on the impact of the determinants on the magnitude of the sensitivity.

The estimation results in Table 10 show that default factor sensitivities are increasing and that the magnitude decreases in the distance-to-default (the coefficients are statistically significant in column 2 and 3, respectively). The result is in accordance with our expectations - the DEF factor is calculated as the return differential between high DD and low DD firms. Hence, not only do firms with low DD have lower returns than firms with high DD, but the 
effect is increasing in magnitude the higher is the default risk. There is just a weak countervailing nonlinear effect, since the coefficients on the squared DD are significant but close to zero.

Most interestingly, the estimation results show that the composition of debt affects systematically the default factor sensitivity. The model comprises firms book leverage (LIABILITIES), the share of bank financing (BANKDEBT), and the interaction term between these two variables. The coefficient on book leverage is insignificant, implying that this ratio does not affect sensitivities, beyond the effect of the market value based leverage captured by the DD.

However, the coefficient on BANKDEBT is significantly different form zero in both regressions. Hence, the composition of debt affects firms' market default risk sensitivity. There are several effects at work, in particular since the interaction term between bank debt and leverage is negative, and the average default risk sensitivity is negative. Overall, having a relationship lender attenuates default risk sensitivity. To illustrate this attenuating effect of firms' bank dependence on default risk sensitivity, Figure 2 shows a plot of the predicted absolute sensitivity of an average firm for varying degrees of BANKDEBT, based on the coefficient estimates shown in Table 10, column 3.

Fig. 2. Default-Risk-Sensitivity and Bank Debt Financing Share This figure shows the predicted DEF-sensitivity based on the absolute sensitivity regression results from Table 10, column 3. The bank share of firm financing is varied over the range of possible values from $[0,1]$, fixing all other variables at their unconditional sample mean.

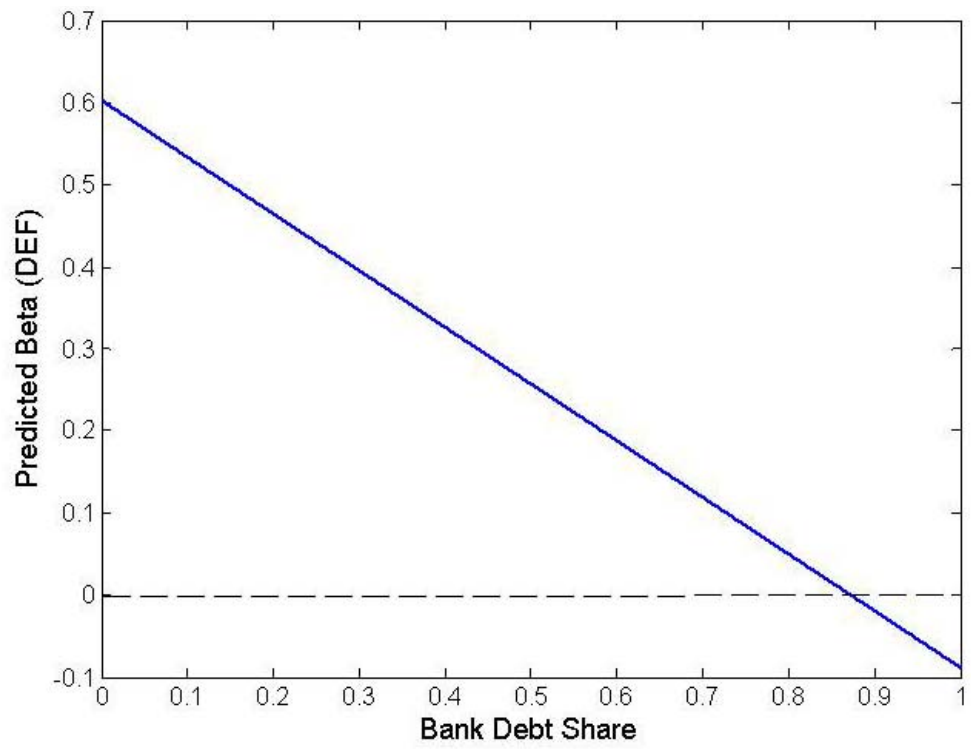

Figure 2 illustrates that the magnitude of the default risk sensitivity for an average firm is lowered the higher the share of bank debt financing of total financing, all else equal. This is in turn consistent with the sensitivity being to some extent driven by information asymmetries and the resulting agency problems of corporate financing. The statistically negative coefficient on the interaction term between BANKDEBT and LIABILITIES implies that there 
is a countervailing effect. All else equal, being more bank dependant reduces the magnitude of default risk sensitivity, but the more the firm is indebted, the less pronounced is this effect.

We interpret these results as evidence consistent with the idea that equity returns are affected by corporate financing characteristics attributable to the financial system firms operate in. Our results suggest that having a relationship lender attenuates the impact of default risk on equity returns. However, these implications rest on the assumption that the share of bank debt of total firm financing is a good proxy for the existence of relationship lending. Clearly, further research is needed to validate our results.

\section{Conclusions}

This study is a first attempt to examine whether the impact of default risk on equity returns depends the financial system firms operate in. We use an implementation of Merton's option-pricing model for the value of equity to estimate firms' default risk based on timely and forward-looking information, and construct a factor that measures the excess return of firms with low default risk over firms with high default risk. We then compare results from asset pricing tests for the U.S. and the German stock market. Since Germany is the prime example of a bank-based financial system, where debt is supposedly a major instrument of corporate governance, we expect that a systematic default risk effect on equity returns should be more pronounced for German rather than U.S. firms.

Using a default risk factor which is measured as a factor-mimicking portfolio, (i.e. the excess return of a portfolio of firms with low default risk over a portfolio of firms with high default risk) bases the asset pricing tests directly on a market price of risk, rather than a measure of the change in aggregate default risk, as in Vassalou and Xing (2004). Our empirical results show the importance of this difference. For both the German and the U.S. capital market, the default risk factor measured as a factor-mimicking portfolio is systematically priced, with firms having low individual default risk earning on average a higher return than firms with high PD (in line with e.g. Ferguson and Shockley (2003) and Dichev (1998)). Moreover, while the Vassalou and Xing (2004) factor is insignificant for the German capital market in general, their factor looses its explanatory power for the U.S. market when simultaneously used with our excess return factor.

The different results depending on the factor construction are somewhat surprising since both factors are based on the same default risk measure (the distance-to-default estimated from equity prices). One possible explanation for the difference might arise from the long/short position in stocks with high or low DD of the factor-mimicking portfolio. For high DD firms, the call option of 
equity owners to receive the firm's assets is far in the money (i.e. default risk is low), and for low DD firms, the corresponding call option is rather at the money. Changes in value will occur mostly linearly related to the underlying change in asset value for high DD stocks (i.e. only the option delta matters), while the change in value for low DD stocks contains a linear component (the delta) and some nonlinear effects (e.g. the vega of the option right). In the long/short portfolio, the linear effects will cancel, while the non-linear component remains. Thus, one candidate explanation for the effect on equity returns that is captured by the factor-mimicking portfolio and not by the average survival rate of firms is the undiversifiable component of changes in asset volatilities. However, this idea clearly requires further research to be substantiated.

Finally, to further examine the influence of financial system characteristics on the impact of default risk on equity returns, we test the hypothesis that having a relationship lender affects firms' default risk sensitivity. We use the share of bank debt of firm financing as a proxy for relationship lending, and find firms' sensitivities to the default risk factor getting attenuated, the more a firm depends on bank debt financing, all else equal. Hence, our evidence suggests that the composition of corporate debt, and thus the financial system environment, bears on the impact of default risk on equity returns. 


\section{Appendix}

In this section, the econometric methods used within this paper are described in detail, based on Cochrane (2005). First, we use a GMM approach to estimate simultaneously the time series and cross sectional test. The following $(K+2)$. $\mathrm{N}$ x 1 system can be used to compute the estimates of the coefficient vector $\Theta:{ }^{22}$

$$
g_{T}(\boldsymbol{\Theta})=\left[\begin{array}{c}
E_{t}\left[\left(\boldsymbol{R}_{t}^{e}-\left[\begin{array}{cc}
\boldsymbol{\alpha} & \boldsymbol{\beta}
\end{array}\right] \boldsymbol{X}_{t}\right) \otimes \boldsymbol{X}_{t}\right] \\
E_{t}\left(\boldsymbol{R}_{t}^{e}-\boldsymbol{\beta} \boldsymbol{\lambda}\right)
\end{array}\right]=\left[\begin{array}{l}
\mathbf{0} \\
\mathbf{0}
\end{array}\right]
$$

where $\mathrm{K}$ denotes the number of factors used in the model ${ }^{23}$ and $\mathrm{N}$ is the number of test assets. $E_{t}$ describes the mean over $t$. The expression $\left[\begin{array}{ll}\boldsymbol{\alpha} & \boldsymbol{\beta}\end{array}\right]=$ $\left[\begin{array}{llll}\boldsymbol{\alpha} & \boldsymbol{\beta}_{\mathbf{1}} & \ldots & \boldsymbol{\beta}_{\boldsymbol{K}}\end{array}\right]$ denotes a matrix consisting of $\boldsymbol{\alpha}$, a $\mathrm{N} x 1$ vector of intercepts and $\boldsymbol{\beta}=\left[\begin{array}{lll}\boldsymbol{\beta}_{1} & \ldots & \boldsymbol{\beta}_{\boldsymbol{K}}\end{array}\right]$ which is a $\mathrm{N} \times \mathrm{K}$ matrix of time-series sensitivities. The variable $\boldsymbol{\lambda}$ describes a $\mathrm{K}$ x 1 vector of cross sectional coefficients. It is important to note that there is no intercept term within our cross sectional approach. $\boldsymbol{R}_{t}^{e}$ identifies the $\mathrm{N}$ x 1 excess return vector with returns of all test asset portfolios $p=\{1 \ldots N\}$ at time $t \in\{1 \ldots T\} . \boldsymbol{X}_{t}^{\prime}=\left[1 X_{2, t} \ldots X_{K+1, t}\right]$ is a horizontal vector composed of 1 and the factor values depending on $t$. The symbol $\otimes$ denotes the Kronecker product and $\Theta$ describes the $((K+1) N+K)$ x 1 parameter vector containing all mentioned parameters.

$$
\Theta^{\prime}=\left[\begin{array}{lllll}
\boldsymbol{\alpha}^{\prime} & \boldsymbol{\beta}_{1}^{\prime} & \ldots & \boldsymbol{\beta}_{K}{ }^{\prime} & \lambda^{\prime}
\end{array}\right]
$$

The system of moment conditions leads to an overidentification (w.r.t. the market risk premia of the factors) since $(K+2) \mathrm{N} \geq(\mathrm{K}+1) \mathrm{N}+\mathrm{K}$.

The GMM estimate can be computed by

$$
\hat{\boldsymbol{\Theta}}=\arg \min _{\boldsymbol{\Theta}} g_{T}(\boldsymbol{\Theta})^{\prime} \hat{\boldsymbol{S}}_{\mathbf{1}}^{-1} g_{T}(\boldsymbol{\Theta})
$$

where ${\hat{\boldsymbol{S}_{1}}}^{-1}$ denotes the estimated inverse spectral density matrix using the Newey and West (1987) approach.

Since in the cross sectional test, portfolio returns are regressed on estimated betas, this test would suffer from an errors-in-variables problem. Estimating the time series and cross-section parameters simultaneously explicitly accounts for this effect of generated regressors, because the standard errors are adjusted accordingly through the use of the optimal weighting matrix in GMM.

\footnotetext{
$\overline{22}$ Vectors or matrices are indicated by bold letters.

${ }^{23}$ Using only the three Fama/French factors, K would be 3.
} 
The moment conditions map the time-series regressions

$$
\boldsymbol{R}^{e i}=\left[\alpha^{i}\left(\boldsymbol{\beta}^{i}\right)^{\prime}\right] \boldsymbol{X}+\boldsymbol{\epsilon}^{i} \quad, \quad i=1 \ldots N
$$

and cross-sectional regressions

$$
\boldsymbol{R}_{t}^{e}=\boldsymbol{\beta} \boldsymbol{\lambda}+e_{t} \quad, \quad t=1 \ldots T
$$

into a GMM system. $\boldsymbol{R}^{e i}$ denotes the T x 1 excess return vector of test asset $i$ whereas $\alpha^{i}$ is the intercept of the portfolio $i$ 's time-series regression. $\boldsymbol{\beta}^{i}$ describes the $\mathrm{K}$ factor sensitivities, $\boldsymbol{X}$ is the usual $\mathrm{T} \times(\mathrm{K}+1)$ factor matrix and $\boldsymbol{\epsilon}^{i}$ is the regression's error term. $\boldsymbol{\lambda}$ denotes a $\mathrm{K} \times 1$ vector of cross-sectional variables. $\boldsymbol{\beta}=\left[\boldsymbol{\beta}^{1}, \ldots, \boldsymbol{\beta}^{N}\right]^{\prime}$ describes the $\mathrm{N} \times \mathrm{K}$ matrix of betas obtained from the time series regression. $\boldsymbol{e}_{t}$ is a $\mathrm{N} \times 1$ error term at time $t$ and the $\mathrm{N} \times 1$ vector $\boldsymbol{R}_{t}^{e}$ denotes again the excess returns of all $N$ test assets at time $t$. Using this approach for the CAPM, the Fama/French model and the two models with additional default factors included, we are able to compare these specifications. It is important to note that the two new models are composed of the three Fama/French factors and just one of the two default factors $\Delta(\mathrm{SV})$ and DEF. Since only the four factor model including DEF employs factors measured as returns, this is our preferred specification.

Second, an asset pricing model can be written in its stochastic discount factor $(\mathrm{SDF})$ form,

$$
p_{t}=E_{t}\left[m_{t+1} \cdot x_{t+1}\right]
$$

where $p_{t}$ is the price at time $t$ for the expected payoff $x_{t+1}$ at $t+1$ multiplied by the stochastic discount factor $m_{t+1}$. Assigned to our models, the form can easily be changed into a $\mathrm{N}$ x 1 system

$$
\mathbf{0}=E_{t}\left[m_{t+1} \cdot \boldsymbol{R}_{t+1}^{e}\right]
$$

where

$$
m_{t+1}=\left[\begin{array}{ll}
a & -\boldsymbol{b}^{\prime}
\end{array}\right] \boldsymbol{X}_{t+1}
$$

and $\boldsymbol{b}$ denotes the $\mathrm{K} \times 1$ parameter vector of the SDF whereas $a$ describes the intercept. If $p_{t}$ is zero, $b$ is identified only up to a constant $(0=E(m x)=$ $E(2 m x))$. In that case Cochrane (1996) proposes to impose $a$ arbitrarily (e.g. $a=1$ ). To compute and test this form, a GMM/discount factor model can be specified with the following moment conditions:

$$
\boldsymbol{g}_{\boldsymbol{T}}(\boldsymbol{b})=E_{t}\left[\left(\boldsymbol{R}_{t}^{e}\right)\left(X_{2, t} \ldots X_{K+1, t}\right) \boldsymbol{b}-\boldsymbol{R}_{t}^{e}\right]
$$


where $\boldsymbol{g}_{\boldsymbol{T}}(\boldsymbol{b})$ is a $\mathrm{N} \mathrm{x} 1$ vector. The optimization problem is very similar to equation (12), that is,

$$
\hat{\boldsymbol{b}}=\arg \min _{\boldsymbol{b}} \boldsymbol{g}_{\boldsymbol{T}}(\boldsymbol{b})^{\prime} \hat{\boldsymbol{S}}_{\mathbf{2}}^{-1} \boldsymbol{g}_{\boldsymbol{T}}(\boldsymbol{b}) .
$$




\section{References}

Altman, Edward I., 1968, Financial ratios, discriminant analysis and the prediction of corporate bankruptcy, Journal of Finance 23, 589-609.

Black, Fischer, and Myron Scholes, 1973, The pricing of options and corporate liabilities, Journal of Political Economy 81, 637-659.

Boot, Arnoud W. A., 2000, Relationship Banking: What Do We Know?, Journal of Financial Intermediation 9, 7-25.

Campello, Murillo, and Long Chen, 2005, Are Financial Constraints Priced? Evidence from Firm Fundamentals Stocks and Bonds, Working paper, University of Illinois.

Carlson, Murray, Adlai Fisher, and Ron Giammarino, 2004, Corporate Investment and Asset Price Dynamics: Implications for the Cross-section of Returns, The Journal of Finance 59, 2577-2603.

Cochrane, John H., 1996, A cross-sectional test of an investment-based asset pricing model, Journal of Political Economy 104, 572-621.

Cochrane, John H., 2005, Asset Pricing. (Princeton University Press Princeton, New Jersey, USA) 2nd edn.

Crosbie, Peter J., and J. R. Bohn, 2003, Modeling Default Risk, Working paper, KMV LLC.

Denis, David J., and Diane K. Denis, 1995, Causes of Financial Distress Following Leveraged Recapitalizations, Journal of Financial Economics 37, 129-157.

Dichev, Ilia D., 1998, Is the Risk of Bankruptcy a Systematic Risk?, Journal of Finance 53, 1131-1147.

Elsas, Ralf, 2005, Empirical Determinants of Relationship Lending, Journal of Financial Intermediation 14, 32-57.

Elsas, Ralf, Mahmoud El-Shaer, and Erik Theissen, 2003, Beta and returns revisited Evidence from the German stock market, Int. Fin. Markets, Inst. and Money 13, 1-18.

Fama, Eugene, and Kenneth French, 1993, Common risk factors in the returns on stocks and bonds, Journal of Financial Economics 33, 3-56.

Fama, Eugene, and Kenneth French, 1996, Multifactor Explanations of Asset Pricing Anomalies, Journal of Finance 51, 55-84.

Ferguson, Michael F., and Richard L. Shockley, 2003, Equilibrium "Anomalies", Journal of Finance 58, 2549-2580.

Furfine, Craig H., and Richard J. Rosen, 2009, Mergers and risk, Working paper, Federal Reserve Bank of Chicago.

Galai, Dan, and Ronald W. Masulis, 1976, The option pricing model and the risk factor of stock, Journal of Financial Economics 3, 53-81.

Garlappi, Lorenzo, and Hong Yan, 2008, Financial Distress and the Cross Section of Equity Returns, Working paper, University of Texas, Austin.

Gorton, Gary, and Frank A. Schmid, 2000, Universal banking and the performance of German firms, Journal of Financial Economics 58, 29-80. 
Griffin, John M., and Michael L. Lemmon, 2002, Book-to-Market Equity, Distress Risk, and Stock Returns, Journal of Finance 57, 2317-2336.

Hansen, Lars Peter, 1982, Large Sample Properties of Generalized Method of Moments Estimators, Econometrica 50, 1029-54.

Ince, Ozgur, and R. Burt Porter, 2006, Individual Equity Return Data From Thomson Datastream: Handle with Care!, Journal of Financial Research 29, 463-479.

Loughran, Tim, and Jay R Ritter, 1995, The New Issues Puzzle, Journal of Finance 50, 23-51.

Merton, Robert C., 1974, On the pricing of corporate debt: the risk structure of interest rates, Journal of Finance 29, 449-470.

Newey, Whitney K., and Kenneth D. West, 1987, Hypothesis Testing with Efficient Method of Moments, International Economic Review 28, 777-787.

Ofek, Eli, and Matthew Richardson, 2003, DotCom Mania: The Rise and Fall of Internet Stock Prices, Journal of Finance 58, 1113-1137.

Ohlson, James, 1980, Financial ratios and the probabilistic prediction of bankruptcy, Journal of Accounting Research 18, 109-131.

Pettengill, Glenn N., Sridhar Sundaram, and Ike Mathur, 1995, The Conditional Relation between Beta and Returns, The Journal of Financial and Quantitative Analysis 30, 101-116.

Ross, Stephen A., 1976, The Arbitrage Theory of Capital Asset Pricing, Journal of Economic Theory 13, 341-360.

Schrimpf, Andreas, Michael Schroeder, and Richard Stehle, 2007, Crosssectional Tests of Conditional Asset Pricing Models: Evidence from the German Stock Market, European Financial Management 13, 880-907.

Shleifer, Andrei, and Robert W. Vishny, 1997, A Survey of Corporate Governance, Journal of Finance 52, 737-783.

Vassalou, Maria, and Yuhang Xing, 2004, Default Risk in Equity Returns, Journal of Finance 59, 831-868.

Zhang, Andrew, 2007, Distress Risk Premia in Stock and Bond Returns, Working paper, Department of Finance, University of Nevada, Las Vegas. 